\title{
Hermetia illucens Protein Conjugated with Glucose via Maillard Reaction: Antioxidant and Techno-Functional Properties
}

\author{
Vusi Vincent Mshayisa (iD) and Jessy Van Wyk \\ Department of Food Science and Technology, Cape Peninsula University of Technology, Bellville 7535, South Africa \\ Correspondence should be addressed to Vusi Vincent Mshayisa; mshayisav@cput.ac.za
}

Received 28 January 2021; Revised 19 March 2021; Accepted 15 April 2021; Published 24 April 2021

Academic Editor: Jaime Yanez

Copyright (c) 2021 Vusi Vincent Mshayisa and Jessy Van Wyk. This is an open access article distributed under the Creative Commons Attribution License, which permits unrestricted use, distribution, and reproduction in any medium, provided the original work is properly cited.

\begin{abstract}
The food industry is considering novel sources of proteins with enhanced functionalities to meet the increasing demand and population growth. Edible insect proteins have emerged as an alternative that is environmentally friendly and economically viable and thus could make a significant contribution to global food security. This study was aimed to establish the effect of conjugation via the Maillard reaction on the antioxidant and techno-functional properties of black soldier fly larvae protein concentrate. Reaction mixtures containing black soldier fly larvae protein concentrate and glucose $(2: 1$ weight ratio) were wetheated at 50,70 , and $90^{\circ} \mathrm{C}$ for $2,4,6,8$, and $10 \mathrm{~h}$, respectively, with an initial $\mathrm{pH}$ of 9 . The results showed that the browning indices of the black soldier fly larvae-glucose (BSFL-Glu) model system increased with an increase in reaction time and temperature, with conjugates formed at $90^{\circ} \mathrm{C}$ exhibiting the highest browning intensity at $420 \mathrm{~nm}$. At $50^{\circ} \mathrm{C}$, the DPPH-RS of the conjugates ranged from 15.47 to $32.37 \%$. The $\mathrm{ABTS}^{+}$radical scavenging activity of BSFL-Glu conjugates produced at $90^{\circ} \mathrm{C}$ exhibited significantly $(p<0.05)$ higher scavenging activity as a function of reaction time. The foaming capacity of BSFL-Glu conjugates produced at $70^{\circ} \mathrm{C}$ showed a significant increase $(p<0.05)$ as a function of reaction time. Principal component analysis was applied to browning and antioxidant indices. Component 1 of the score plot accounted for $89 \%$, while component 2 accounted for $8 \%$ of the observed variability and allowed discrimination/differentiation of the samples based on the heating temperature. These findings provide a practical means to improve the functionality of novel edible insect proteins for food application.
\end{abstract}

\section{Introduction}

The predicted population increase to 9 billion people by the year 2050 presents a considerable threat to global food security. This is exacerbated by climate change, energy crises, and the consumption and demand patterns for good quality protein for human consumption $[1,2]$. Edible insects have been proposed as an alternative food protein source that can address the current and future nutritional, health, economic, and food security concerns [3-5]. With the growing interest in edible insect protein consumption, industrial farming of species such as mealworm larvae (Tenebrio molitor) and black soldier fly larvae (Hermetia illucens), which are high in protein content, has been expanding due to investment in research and development, leading to a stable supply, consistent quality, cost-effectiveness, and hygienic production. Proteins extracted from edible insects and used in food applications as functional ingredients (in powder form or paste) may have greater success in terms of acceptance for human consumption since the willingness to consume whole insects is low $[6,7]$.

Apart from the nutritional value, food proteins provide unique techno-functional properties which affect their behaviour in food systems during preparation, processing, storage, and consumption and contribute to the quality and sensory attributes of food. To further promote the application of edible insects proteins in food applications, physical [8], chemical [9], and enzymatic [10] methods have been explored to enhance their techno-functional properties. Due to the potential health hazards brought in by chemical 
modifications, most of these techniques cannot be applied in food processing. Furthermore, it is difficult to widely apply physical modification as it involves mechanical forces such as high pressure or shear [11].

In the last decade, the Maillard reaction-a nonenzymatic chemical reaction between a carbonyl compound (usually a reducing sugar) and protein amino groups-has been reported to remarkably improve the techno-functional properties of proteins and even endows them with novel functionality. The Maillard reaction (MR) leads to the formation of protein-sugar conjugates with the enhanced emulsifying ability [12], solubility, antibacterial, antioxidant properties [13, 14], and even alleviates the allergenicity of proteins [15-17]. As reported by Medrano et al. [18], glycation of $\beta$-lactoglobulin with glucose exhibited improved foaming stability, suggesting increased adsorption to the air/water interface. Conjugates with superior emulsion properties were also reported by Diftis and Kiosseoglou [19].

There is now comprehensive scientific evidence showing that protein techno-functionality can be substantially improved without the use of any chemical reagents by covalent coupling with saccharides via the MR, thereby making this technique safe. [20-23]. The rate and degree of the MR are influenced by various factors such as temperature, time, relative humidity $(\mathrm{RH}), \mathrm{pH}$, and the molar ratio of the reactants, hence the nature of the products produced and their functional properties [24]. Recently, various scientific publications have studied the effect of heating temperature on the functional properties of conjugates generated from fructose-lysine and ribose-lysine [25], coconut sap [26], bovine serum albumin-glucose [15], and whey protein isolate with xylooligosaccharide [13] model systems. Guérard and Sumaya-Martinez [27] reported that the antiradical scavenging effect was improved by $75 \%$ when casein peptone and cod viscera hydrolysate were heated in the presence of glucose. However, there is a paucity of information about the effect of conjugation on the antioxidant activity and technofunctional properties of edible insect proteins extracted from black soldier fly larvae (BSFL). Since the Maillard glycation between reducing sugars and amino acids/proteins is inevitable during thermal food processing and manufacturing, it is imperative to understand its effect on novel proteins extracted from edible insects.

Therefore, this study was aimed to investigate the effect of conjugation time and temperature on the antioxidant activity and techno-functional properties of black soldier fly larvae (BSFL) protein with the view to find alternative protein sources for food application. This study will extend current knowledge of the functionality changes of insect proteins due to the Maillard reaction.

\section{Materials and Methods}

2.1. Chemicals. All chemicals were purchased from SigmaAldrich (Aston Manor, South Africa). Prepared reagents were stored under conditions that prevented contamination or deterioration. The water used in the study was ultrapure water purified with a Milli-Q water purification system (Millipore, Microsep, South Africa).
2.2. BSFL Protein Extraction. Defatted BSFL flour (BSFL-DF) was mixed with Milli-Q water at a ratio of $1: 10\left(w \cdot w^{-1}\right)$, and the $\mathrm{pH}$ of the mixture was adjusted immediately to $\mathrm{pH} 10$ using a 0.1 or $1 \mathrm{~N} \mathrm{NaOH}$ solution. The mixture was stirred on a laboratory magnetic stirrer at a rate designed to prevent the formation of a vortex, for $30 \mathrm{~min}$ at ambient temperature $\left(25^{\circ} \mathrm{C} \pm 1.0\right)$. Subsequently, the samples were centrifuged at $10000 \mathrm{~g}$ for $20 \mathrm{~min}$ at $4^{\circ} \mathrm{C}$. Next, the $\mathrm{pH}$ of the supernatants was adjusted to 4.5 with $1 \mathrm{M} \mathrm{HCl}$, and then, the suspension was left at $4^{\circ} \mathrm{C}$ overnight to facilitate protein precipitation. The precipitated proteins were recovered by centrifugation at $10000 \mathrm{~g}$ for $30 \mathrm{~min}$ at $4^{\circ} \mathrm{C}$. The $\mathrm{BSFL}$ protein concentrate was then freeze-dried and stored at $-20^{\circ} \mathrm{C}$ for further analysis.

2.3. Synthesis of BSFL-Glu Conjugates, pH, and Browning Index. Black soldier fly larvae protein and glucose (BSFLGlu) conjugates were prepared according to the method of Vhangani and Van Wyk [25] and Mshayisa [28] with slight modifications. BSFL protein concentrate and glucose $(2: 1$ $w \cdot w^{-1}$ ) were dissolved in $100 \mathrm{~mL}$ of $0.1 \mathrm{M}$ phosphate buffer at $\mathrm{pH}$ 9. The samples were transferred into $250 \mathrm{~mL}$ Schott bottles and heated at 50,70 , and $90^{\circ} \mathrm{C}$ in a water bath for 2 , $4,6,8$, and $10 \mathrm{~h}$, respectively. After the heating period had elapsed, the resulting BSFL-Glu conjugates were immediately cooled in an ice bath. An unheated BSFL-Glu solution $(0 \mathrm{~min})$ was prepared as the control. A portion of the BSFLGlu conjugates in solution was retained for $\mathrm{pH}$ measurements ( $\mathrm{pH}$ meter: Metrohm, Switzerland). The remainder of the solutions were freeze-dried (Virtis, Wizard 2.0, NY, USA) and stored in airtight screw-capped glass bottles at $-80^{\circ} \mathrm{C}$ until analysis. Before use, the powder was reconstituted to the required concentration with Milli-Q water and browning intensity was measured with a spectrophotometer (Lambda 25, Perkin Elmer, Singapore) at 294 and $420 \mathrm{~nm}$. The $\mathrm{pH}$ and browning intensity (BI) measurements were used as nonspecific indicators of the MR.

\subsection{Determination of Antioxidant Activity of BSFL- Glu Conjugates}

2.4.1. DPPH Radical Scavenging Activity. The DPPH radical scavenging (DPPH-RS) activity of BSFL-Glu conjugates was determined according to the method of Lertittikul et al. [28, 29] with slight modifications. A $0.12 \mathrm{mM}$ solution of DPPH in ethanol was prepared daily and protected from light. A $4 \mathrm{~mL}$ aliquot of DPPH solution was added to $2 \mathrm{~mL}$ of BSFLGlu conjugate $\left(10 \mathrm{mg} \cdot \mathrm{mL}^{-1}\right)$ samples. The mixture was vortexed (Vortex-Genie 2, Scientific Industry Inc., USA) and allowed to stand at ambient temperature in the dark for $30 \mathrm{~min}$. The absorbance of the mixtures was measured at $517 \mathrm{~nm}$ with a spectrophotometer (Lambda 25, Perkin Elmer, Singapore). A reaction mixture containing $2 \mathrm{~mL}$ distilled water and $4 \mathrm{~mL}$ ethanolic DPPH solution was used as control. All measurements were performed in triplicate. The percentage of DPPH-RS radical scavenging activity was calculated using the following equation:

$$
\% \mathrm{DPPH}-\mathrm{RS}=1-\frac{A_{\text {sample }(517 \mathrm{~nm})}}{A_{\text {control }(517 \mathrm{~nm})}} \times 100,
$$


where $A_{\text {control }}$ is the absorbance of the control at $517 \mathrm{~nm}$ and $A_{\text {sample }}$ is the absorbance of the sample at $517 \mathrm{~nm}$.

2.4.2. ABTS $^{+}$Radical Scavenging Activity. The spectrophotometric analysis of $\mathrm{ABTS}^{\bullet+}$ radical scavenging (ABTS-RS) activity of BSFL-Glu conjugates was determined according to a method as described by Yu et al. $[28,30]$ with slight modifications. The ABTS radical was prepared by reacting $7 \mathrm{mmol} . \mathrm{L}^{-1}$ ABTS solution and $2.45 \mathrm{mmol} . \mathrm{L}^{-1}$ potassium persulphate solution in equal volume, and the mixture was allowed to stand overnight in the dark at ambient temperature. The ABTS solution was diluted twenty-fold (20-fold) with Milli-Q water to obtain an absorbance of 1.5-1.6 at $730 \mathrm{~nm}$. Fresh ABTS was prepared daily. A $4 \mathrm{~mL}$ aliquot of diluted ABTS solution was added to $200 \mu \mathrm{L}$ of aqueous BSFL-Glu conjugates solution $\left(10 \mathrm{mg} \cdot \mathrm{mL}^{-1}\right)$, and the mixture was allowed to stand at room temperature for one hour. The absorbance was then measured at $730 \mathrm{~nm}$ using a spectrophotometer (Lambda 25, Perkin Elmer, Singapore). The control was prepared in the same manner with the substitution of distilled water for the sample. All measurements were performed in triplicate. The percentage of ABTS radical scavenging activity was calculated according to the following equation:

$$
\% \mathrm{ABTS}-\mathrm{RS}=\frac{A_{\text {control }(730 \mathrm{~nm})}-A_{\text {sample }(730 \mathrm{~nm})}}{A_{\text {control }(730 \mathrm{~nm})}} \times 100,
$$

where $A_{\text {control }}$ is the absorbance of the control at $730 \mathrm{~nm}$ and $A_{\text {sample }}$ is the absorbance of the sample at $730 \mathrm{~nm}$.

2.4.3. Reducing Power. The reducing power (RP) was determined according to the method of Vhangani and Van Wyk [25] and Mshayisa [28] with slight modifications. A one millilitre aliquot of each BSFL-Glu conjugates sample $\left(10 \mathrm{mg} \cdot \mathrm{mL}^{-1}\right)$ was mixed with $2.5 \mathrm{~mL}$ of $0.2 \mathrm{M}$ sodium phosphate buffer $(\mathrm{pH} 6.6)$ and $2.5 \mathrm{~mL}$ of $1.0 \%$ potassium ferricyanide. The reaction mixtures were incubated in a temperature-controlled water bath at $50^{\circ} \mathrm{C}$ (Memmert, Germany) for $30 \mathrm{~min}$, followed by the addition of $2.5 \mathrm{~mL}$ of $10 \%$ trichloro-acetic acid after cooling at room temperature. The mixture was centrifuged at $1750 \mathrm{~g}$ for $10 \mathrm{~min}$ at $25^{\circ} \mathrm{C}$. The supernatant obtained $(2.5 \mathrm{~mL})$ was treated with $1 \mathrm{~mL}$ of Milli-Q water and $0.5 \mathrm{~mL}$ of $0.1 \%$ Ferric chloride. The absorbance of the reaction mixture was measured at $700 \mathrm{~nm}$ in a spectrophotometer (Lambda 25, Perkin Elmer, Singapore). All measurements were performed in triplicate. The RP was expressed as an increase in absorbance at $700 \mathrm{~nm}$.

2.4.4. Determination of Iron Chelation Activity. The Chelating activity of BSFL-Glu conjugates was determined according to the method of $\mathrm{Gu}$ et al. [31] with slight modifications. One millilitre BSFL-Glu conjugate sample (10 mg.mL $\mathrm{mL}^{-1}$ ) was mixed with $1.85 \mathrm{~mL}$ of Milli-Q water and $0.05 \mathrm{~mL} 2.0 \mathrm{mM} \mathrm{FeCl}_{2}$, and the mixture was allowed to stand at room temperature for $30 \mathrm{~s}$. The reaction mixture thus obtained was added to $0.1 \mathrm{~mL}$ of $0.5 \mathrm{mM}$ ferrozine and mixed; the absorbance was measured at $562 \mathrm{~nm}$ using a spec- trophotometer (Lambda 25, Perkin Elmer, Singapore) after $10 \mathrm{~min}$ resting time and $5 \mathrm{~min}$ centrifugation at $3000 \mathrm{~g}$. The control was prepared in a similar manner, except that BSFL-Glu conjugates were replaced with Milli-Q water. All measurements were performed in triplicate. The percentage of chelating activity was calculated as follows:

$$
\% \text { Chelating activity }=1-\frac{A_{\text {sample }(562 \mathrm{~nm})}}{A_{\text {control }(562 \mathrm{~nm})}} \times 100 \text {, }
$$

where $A_{\text {control }}$ is the absorbance of the control at $562 \mathrm{~nm}$ and $A_{\text {sample }}$ is the absorbance of the sample at $562 \mathrm{~nm}$.

\subsection{Analysis of Techno-Functional Properties}

2.5.1. Foaming Property Evaluation. Foaming capacity (FC) and foam stability (FS) were determined according to the method of Zielińska et al. [32] with minor modifications. The freeze-dried BSFL-Glu conjugates sample was dispersed in distilled water $\left(5 \% w \cdot v^{-1}\right)$ and centrifuged (Thermo Electron Corporation Jouan MR1812) at $10000 \mathrm{rpm}$ for $15 \mathrm{~min}$. Then, $20 \mathrm{~mL}$ of the supernatant was homogenized in a high shear homogenizer mixer (Polytron PT 2500E) at a speed of $16000 \mathrm{rpm}$ for $3 \mathrm{~min}$. The whipped sample was immediately transferred into a $50 \mathrm{~mL}$ cylinder. The total volume was read at time zero and $30 \mathrm{~min}$ after homogenization. The foaming capacity and foam stability were calculated from the formula:

$$
\begin{gathered}
\text { Foaming Capacity }(\mathrm{FC})=\frac{V_{a}-V}{V} \times 100, \\
\text { Foaming stability }(\mathrm{FS})=\frac{V_{30}}{V_{a}} \times 100,
\end{gathered}
$$

where $V$ is the volume before whipping $(\mathrm{mL}), V_{a}$ is the volume after whipping $(\mathrm{mL})$, and $V_{30}$ is the volume after standing $(\mathrm{mL})$.

2.5.2. Emulsion Capacity and Stability of Conjugates. Emulsifying properties were determined according to the method of Coelho and Salas-Mellado [33] and Anzani et al. [34] with slight modifications. The sample was dispersed in distilled water $\left(5 \% w \cdot v^{-1}\right)$ and centrifuged (Thermo Electron Corporation Jouan MR1812) at $9000 \mathrm{rpm}$ speed for $15 \mathrm{~min}$; $15 \mathrm{~mL}$ of the supernatant was homogenized (Polytron PT $2500 \mathrm{E}$ ) with $15 \mathrm{~mL}$ of commercial sunflower oil at a speed of $18000 \mathrm{rpm}$ for $1 \mathrm{~min}$. Next, the samples were centrifuged at $3000 \mathrm{~g}$ for five minutes, and the volume of the individual layers was read. Emulsion stability was evaluated by heating the emulsion in a water bath set at $80^{\circ} \mathrm{C}$ for $30 \mathrm{~min}$. Then, the samples were centrifuged at $3000 \mathrm{~g}$ for five min. Emulsion capacity and emulsion stability were calculated from the formula:

$$
\begin{aligned}
& \text { Emulsion capacity }(\mathrm{EC})=\frac{V_{\mathrm{el}}}{V} \times 100 \\
& \text { Emulsion stability }(\mathrm{ES})=\frac{V_{30}}{V_{\mathrm{el}}} \times 100
\end{aligned}
$$


where $V$ is the total volume of tube contents, $V_{\mathrm{el}}$ is the volume of the emulsified layer, $V_{30}$ is the volume of the emulsified layer after heating.

2.6. Data Analysis. All data were subjected to multivariate analysis of variance (MANOVA) using SPSS for Windows ${ }^{\circledR}$, version 26.0 (IBM Corp, New York, USA) to ascertain whether the main effects resulted in significant differences in response variables. Duncan's multiple comparison post hoc test was used to test significant differences $(p<0.05)$ between individual means. Principal component analysis (PCA) was performed on aggregated mean centred data for antioxidant indices and techno-functional properties using Singular Value Decomposition (SVD) algorithm and crossvalidation methods with 18 segments to determine potential clusters with the use of The Unscrambler software, version 11 (CAMO Software, Oslo, Norway). Graphs and figures were generated using the Origin software, version 9.60 (Origin labs, Northampton, MA, USA) and The Unscrambler software.

\section{Results and Discussion}

3.1. The Extent of Maillard Reaction. During the Maillard reaction (MR), the initial reactants are consumed which consequently results in the formation of initial, intermediate, and advanced brown polymers. The initial condensation step of the MR is facilitated by higher $\mathrm{pH}$ values, and thus, it is vital to monitor the $\mathrm{pH}$ of the model system. Therefore, change in $\mathrm{pH}$ values during the MR was monitored to evaluate its significance during the reaction. The $\mathrm{pH}$ of BSFL-Glu conjugate model systems at 50,70 , and $90^{\circ} \mathrm{C}$ as a function of reaction time is shown in Figure 1. For each model system, the MANOVA with Duncan's multiple range tests revealed that the decrease in $\mathrm{pH}$ observed as the reaction temperature and time increased was significant $(p<0.05)$. This indicated that the largest $\mathrm{pH}$ reduction resulted from higher reaction temperature and time combinations. As shown in Figure 1, the final $\mathrm{pH}$ values of BSFL-Glu conjugates reacted at $90^{\circ} \mathrm{C}$ were lower than those at $50^{\circ} \mathrm{C}$ and $70^{\circ} \mathrm{C}$, respectively. These results are due to the fact that the degree of the Maillard reaction was greater at high temperatures than at low temperatures. Vhangani and Van Wyk [25] also observed a decrease in $\mathrm{pH}$ of MRPs from fructose-lysine and ribose-lysine model systems. Moreover, Benjakul et al. [35] also reported a decrease in $\mathrm{pH}$ of porcine plasma protein-sugar model systems heated up to 5 hours. In the early stages of the reaction, the decrease in $\mathrm{pH}$ can be due to the formation of formic and acetic acid during the $\mathrm{MR}[36,37]$ and the free amino groups of BSFL protein consumed. Additionally, higher $\mathrm{pH}$ was further away from the BSFL protein concentrate's isoelectric point and could therefore induce stronger intramolecular electrostatic repulsions that may lead to more extensive unfolding, more exposed reactant amino groups, and greater solubility, both of which contribute to improving the conjugation reaction.

3.2. Browning Intensity. The UV-VIS absorption of Maillard reaction products (MRPs) at $294 \mathrm{~nm}$ and $420 \mathrm{~nm}$ has been generally accepted as nonspecific markers to evaluate the for-

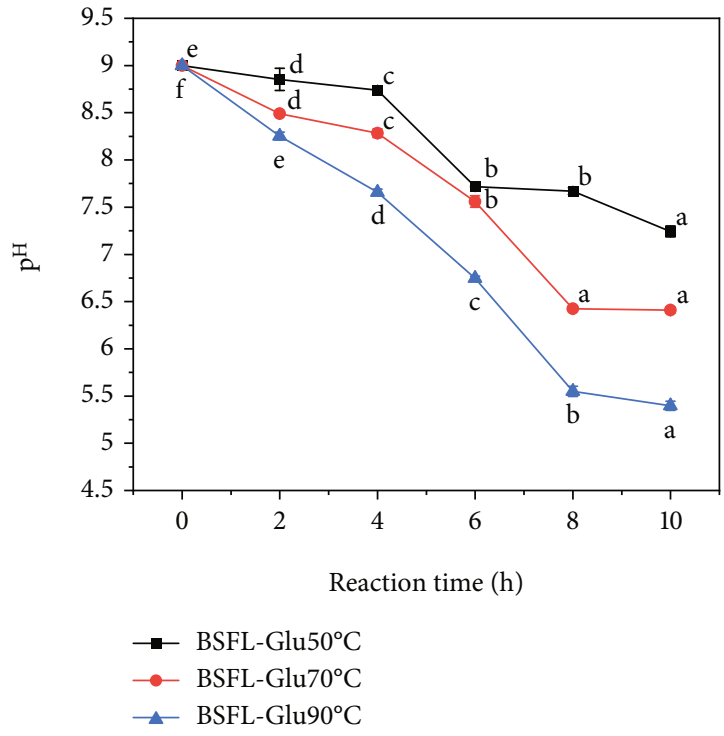

FIGURE 1: Changes in $\mathrm{pH}$ of BSFL-GLu conjugates model system as a function of reaction time. Values are mean \pm standard deviation; means with different superscript are significantly different at the same heating temperature.

mation of Amadori compounds at the early-intermediate stage and melanoidins at the final stage. In the early stage of the MR, intermediate compounds are formed. The early to intermediate stage Amadori reaction products with characteristic absorption at $294 \mathrm{~nm}$ and advanced stage melanoidins which represent brown pigments at $420 \mathrm{~nm}$ are usually measured as an indicator of the extent of the MR in model systems. As shown in Figures 2(a)-2(c), a gradual increase in absorbance at $294 \mathrm{~nm}$ was observed as the reaction time increased at the same reaction temperature up to $10 \mathrm{~h}$, indicating that the increase of the reaction time increases the formation of intermediate Maillard reaction products. BSFLGlu conjugates prepared at higher reaction temperature $\left(90^{\circ} \mathrm{C}\right)$ exhibited the highest increase $(p<0.05)$ in absorbance as a function of reaction time. The absorbance at $294 \mathrm{~nm}$ was used to determine the intermediate compounds of the MR [35]. From these results, the increase in absorbance at $294 \mathrm{~nm}$, irrespective of heating temperature, suggests that the early intermediate compounds were dominant in all BSFL-Glu conjugates.

The easiest observable result of the Maillard reaction is brown colour production (A420 nm) since it gives a visual estimate. Its magnitude is also used in foods as a measure of the degree to which the Maillard reaction occurs and signifies an advanced stage of the Maillard reaction [38]. As the heating time increased $(p<0.05)$ irrespective of the heating temperature (Figures 2(a)-2(c)), an increase in browning of BSFL-Glu MRPs as measured by absorbance at $420 \mathrm{~nm}$ was observed. The increase in absorbance at $420 \mathrm{~nm}$ indicates the development of browning pigment in the final stage of the Maillard reaction [39]. The reaction consists of the condensation of an amino compound and sugar fragments into polymerised glycoproteins and the brown pigment melanoidin. As evidenced by the increased absorption at $294 \mathrm{~nm}$, the increase in brown pigment production was coincidental 


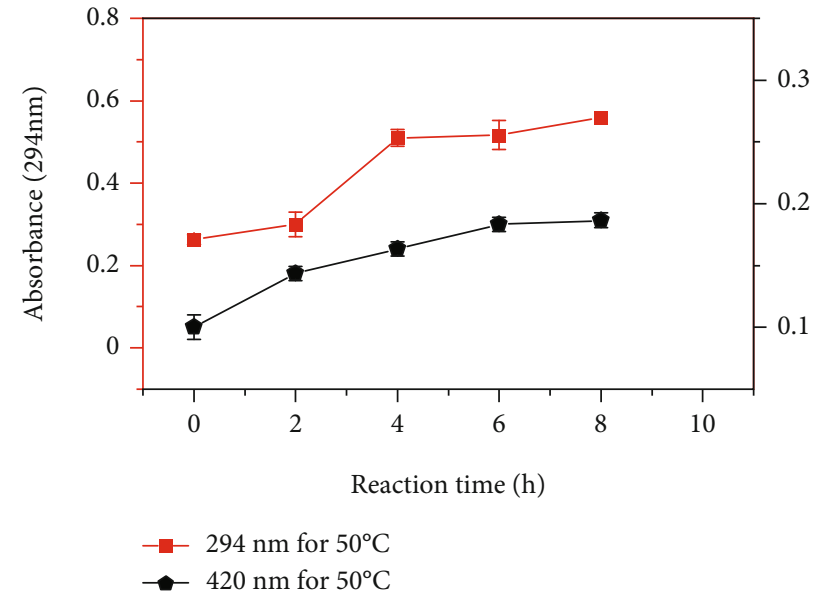

(a)

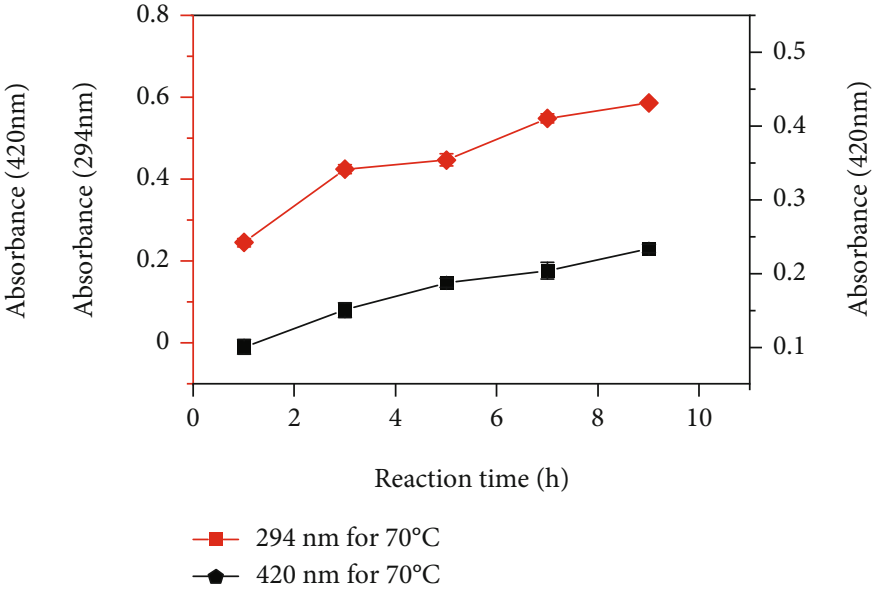

(b)

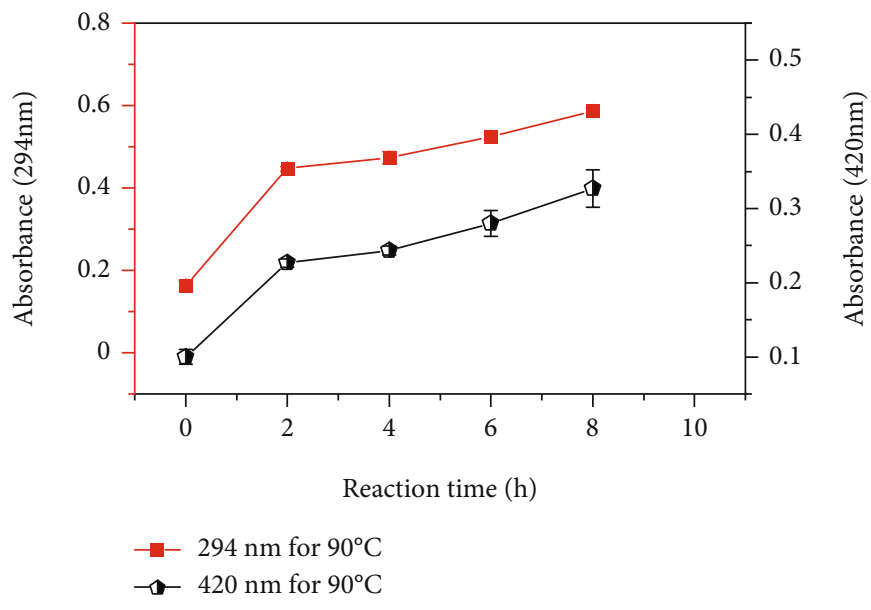

(c)

Figure 2: Changes in absorbance at $294 \mathrm{~nm}$ and $420 \mathrm{~nm}$ of BSFL-Glu conjugates as a function of reaction time: (a) $50^{\circ} \mathrm{C}$, (b) $70^{\circ} \mathrm{C}$, and (c) $90^{\circ} \mathrm{C}$.

with an increase in colourless intermediate formation, which indicates that brown pigments were developed proportionally with the intermediate products produced (Figures 2(a)$2(\mathrm{c})$ ). These findings suggest that, under mild incubation conditions, the formation of intermediate Amadori compounds takes place prior to coloured melanoidins.

\section{Antioxidant Properties}

According to Vhangani and Van Wyk [40], it is vital to implement more than one type of assay to evaluate the antioxidant activity of the products formed during the Maillard reaction. This is due to the complexity and nature of the myriad of the formed intermediate compounds which have not yet been fully elucidated. Thus, the antioxidant activity of heat-treated BSFL-Glu conjugates was assayed in terms of their free radical-scavenging activity, reducing power and metal chelation.

4.1. DPPH Radical Scavenging. The DPPH-RS activity indicates the hydrogen-donating ability of antioxidants. The
DPPH-RS of BSFL-Glu conjugates is presented in Figure 3. In general, the DPPH-RS of BSFL-Glu conjugates increased significantly $(p<0.05)$ with an increase in reaction time at 50,70 , and $90^{\circ} \mathrm{C}$, respectively. At $50^{\circ} \mathrm{C}$, the DPPH-RS of the conjugates ranged from 15.47 to $32.37 \%$, and it was significantly higher than the control $(t=0)$. Compared with the lower temperatures $\left(50\right.$ and $\left.70^{\circ} \mathrm{C}\right)$, conjugates produced at $90^{\circ} \mathrm{C}$ had a significantly higher DPPH radical scavenging activity $(p<0.05)$. BSFL protein concentrate heated alone exhibited a weak radical scavenging activity with only $3 \%$ radical activity and there was no significant difference $(p>0.05)$ over the reaction conditions (time and temperature) examined in this study (results not shown). This signifies that BSFL protein conjugated with glucose can significantly improve the antioxidant activity of BSFL protein.

The results of this study are in agreement with Jiang et al. [41] who observed an increase in DPPH-RS of the tripeptide Ile-Pro-Pro (IPP) MRPs as a function of reaction time. Moreover, ultrafiltered casein-glucose MRPs model systems showed strong DPPH radical scavenging [42]. Taken 


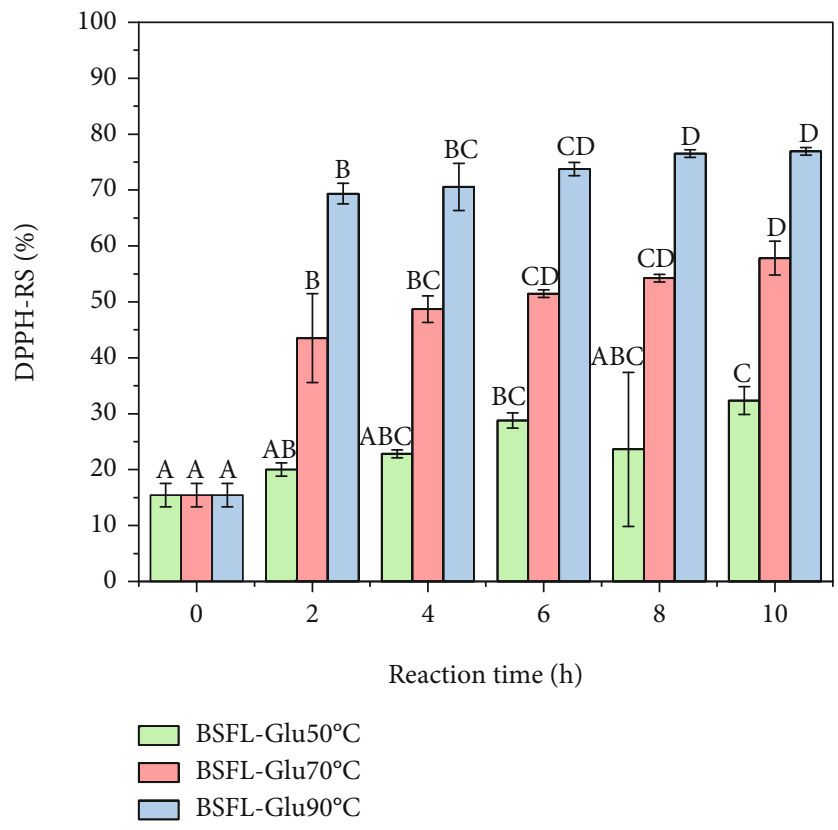

FIGURE 3: DPPH radical scavenging activity of BSFL-Glu conjugates as a function of reaction temperature. Values are mean \pm standard deviation; means with different superscripts are significantly $(p<0.05)$ different at the same heating temperature.

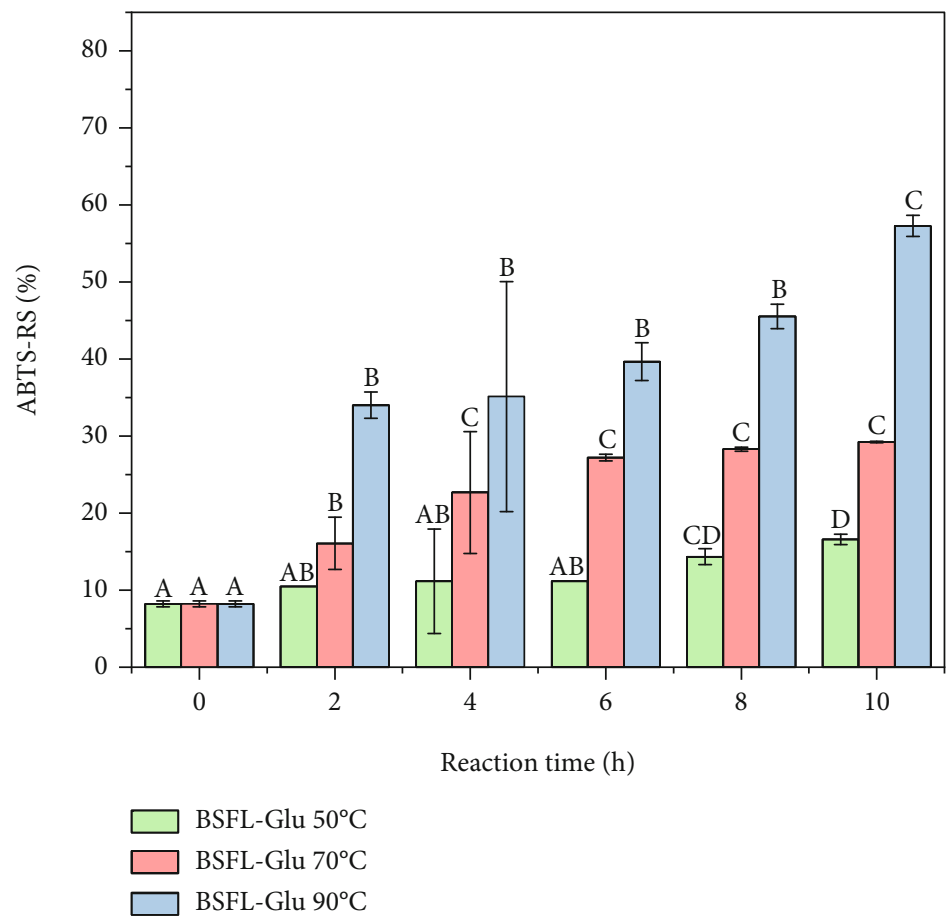

FIGURE 4: ABTS radical scavenging activity of BSFL-Glu MRPs as a function of reaction temperature. Values are mean \pm standard deviation; means with different superscript are significantly different at the same heating temperature.

collectively, the results of this study show that conjugates prepared from insect protein concentrate extracted from BSFL possess hydrogen-donating capacity, which implies that these conjugates exhibit potency to react with free radicals. This opens up new avenues or possibilities for the application of insect proteins as novel functional ingredients in food formulations.
4.2. ABTS Radical Scavenging. The $\mathrm{ABTS}^{+}$radical scavenging activity was determined in order to assess the antioxidant potential of BSFL-Glu conjugates. As depicted in Figure 4, the $\mathrm{ABTS}^{+}$radical scavenging activity of conjugates produced at $50^{\circ} \mathrm{C}$ ranged from 10.5 to $16.5 \%$ and exhibited the lowest ABTS radical scavenging activity. This can be attributed to the electron-donating ability of some of the amino acids of 
BSFL protein, which reduces $\mathrm{ABTS}^{+}$radicals to offer weak antioxidant activity. However, increasing the temperature to $70^{\circ} \mathrm{C}$ increases significantly $(p<0.05)$ the $\mathrm{ABTS}^{+}$radical scavenging activity as a function of reaction time. The results of this study concur with You et al. [36] who reported that the $\mathrm{ABTS}^{+}$radical scavenging activity of a silver carp protein hydrolysate-glucose system obtained at $60^{\circ} \mathrm{C}$ was significantly higher than that obtained at $50^{\circ} \mathrm{C}$.

The $\mathrm{ABTS}^{+}$radical scavenging activity of BSFL-Glu conjugates produced at $90^{\circ} \mathrm{C}$ exhibited significantly $(p<0.05)$ higher scavenging activity as a function of reaction time (Figure 4). Sun et al. [43] reported that the MRPs formed by $\alpha$-lactalbumin and different types of reducing sugars exhibited greater ABTS-RS than native $\alpha$-lactalbumin. The browning compounds formed during the Maillard reaction, which are primarily composed of melanoidins, have been reported to be significant contributors to the radical scavenging ability $[36,44]$. The results of this study strongly confirm that glycation could induce the antioxidant activity of the edible insect protein, the intensity of which depends on the duration of reaction time and temperature. To the best of our knowledge, this is the first study to explore the effect of reaction temperature and time on the antioxidant properties of BSFL-Glu conjugates.

4.3. Changes in Reducing Power. Reducing power has been used to determine the antioxidant effect of MRPs, and it is regarded as a good indicator of antioxidant activity of food components [45]. This assay measures particularly the antioxidant activity of MRP conjugates with the hydroxyl groups of conjugates playing a role in the reducing activity through their redox potential of transferring electrons $[25,45]$. In this assay, in the presence of antioxidants, the ferric chloride/ferricyanide complex is reduced to the ferrous form $\left(\mathrm{Fe}^{2+}\right)$, and the $\mathrm{Fe}^{2+}$ concentration can, therefore, be assessed spectrophotometrically by measuring the Prussian blue colour of Perl at $700 \mathrm{~nm}$. The reducing power of BSFL-Glu conjugates increased significantly $(p<0.05)$ with an increase in reaction time, with conjugates derived at $50^{\circ} \mathrm{C}$ and $70^{\circ} \mathrm{C}$ (Table 1) having the lowest and highest reducing power, respectively. Heat-induced MRPs from ribose-lysine [25], glucose-glycine [46], and porcine plasma protein-glucose $[29,35]$ model systems also possessed reducing power. From these results, the reducing power of BSFL-Glu conjugates increases as a function of reaction time at all temperatures and this correlated well with browning intensity (Figure 2). The increase in reducing power at higher temperatures $\left(90^{\circ} \mathrm{C}\right)$ can be ascribed to the fact that the protein structure was unravelled (denatured) at elevated temperatures, enhancing the Maillard reaction rate, and producing more intermediate and advanced products, with enhanced reducing power (Table 1). Moreover, the results of DPPH-RS and ABTS-RS assays together with the reducing power results indicated that the difference in the antioxidant activity of the conjugates from this edible insect protein was mainly attributable to the mechanism of single electron transfer (SET). Conjugation of BSFL protein with glucose via the Maillard reaction may induce structural changes in the BSFLGlu system, which result in the formation of products or compounds that contribute to the reducing power.
TABLE 1: Changes in reducing power of BSFL-Glu conjugates as a function of reaction time and temperature $(700 \mathrm{~nm})$.

\begin{tabular}{lccc}
\hline \multirow{2}{*}{ Reaction time (h) } & \multicolumn{3}{c}{ Reaction temperature } \\
& $50^{\circ} \mathrm{C}$ & $70^{\circ} \mathrm{C}$ & $90^{\circ} \mathrm{C}$ \\
\hline 0 & $0.02 \pm 0.01^{\mathrm{a}}$ & $0.12 \pm 0.01^{\mathrm{a}}$ & $0.41 \pm 0.03^{\mathrm{a}}$ \\
2 & $0.04 \pm 0.00^{\mathrm{b}}$ & $0.33 \pm 0.02^{\mathrm{b}}$ & $0.76 \pm 0.04^{\mathrm{b}}$ \\
4 & $0.05 \pm 0.00^{\mathrm{b}}$ & $0.34 \pm 0.01^{\mathrm{b}}$ & $0.80 \pm 0.03^{\mathrm{b}}$ \\
6 & $0.06 \pm 0.00^{\mathrm{c}}$ & $0.38 \pm 0.01^{\mathrm{c}}$ & $0.83 \pm 0.03^{\mathrm{b}, \mathrm{c}}$ \\
8 & $0.07 \pm 0.01^{\mathrm{d}}$ & $0.41 \pm 0.01^{\mathrm{d}}$ & $0.81 \pm 0.04^{\mathrm{b}}$ \\
10 & $0.11 \pm 0.01^{\mathrm{e}}$ & $0.42 \pm 0.01^{\mathrm{d}}$ & $0.89 \pm 0.06^{\mathrm{c}}$ \\
\hline
\end{tabular}

${ }^{a}$ Values are the mean $\pm \mathrm{SD}(n=3)$; values with different superscript in the same column indicate significant differences $(p<0.05)$.

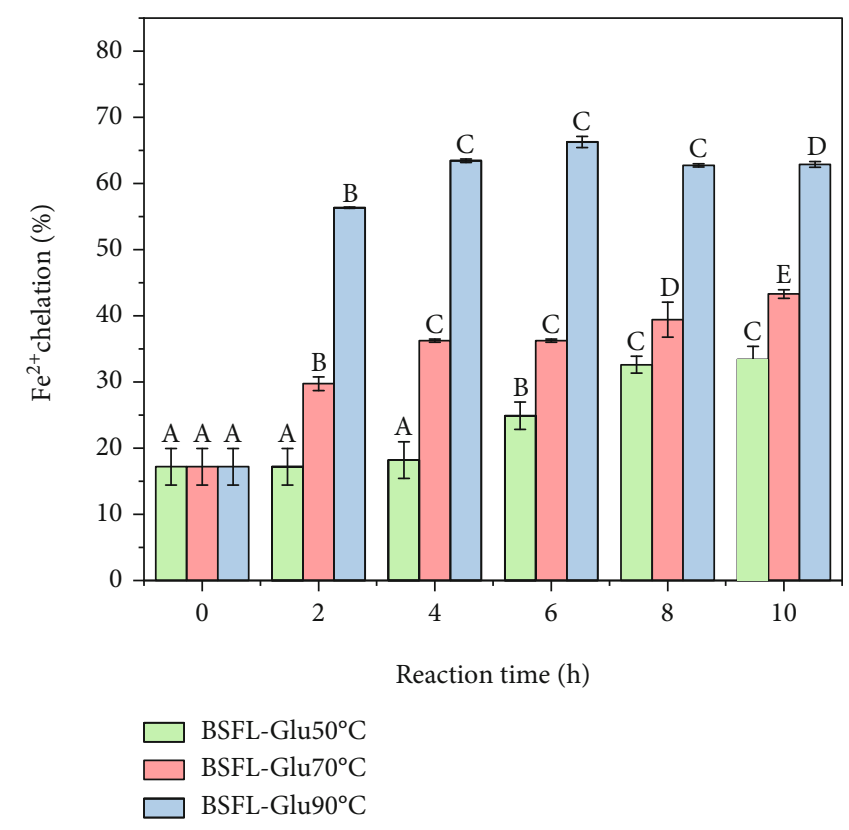

FIgURE 5: Iron chelating activity of BSFL-Glu conjugates as a function of reaction time. Values are mean \pm standard deviation; means with different superscript are significantly different at the same heating temperature.

4.4. $\mathrm{Fe}^{2+}$ Chelating Activity. The generation of reactive oxygen species such as hydroxyl radical $\left({ }^{\bullet} \mathrm{OH}\right)$ and superoxide anion $\left(\mathrm{O}_{2}{ }^{--}\right)$can be catalysed by transition metal ions, such as $\mathrm{Fe}^{2+}$ and $\mathrm{Cu}^{2+} \cdot \mathrm{Fe}^{2+}$, in particular, generates the hydroxyl radical through the Fenton reaction that accelerates the reaction of the lipid peroxidation reaction. Chelators can form complexes with metal ions and inhibit the Fenton reaction. Consequently, the chelation of metal ions contributes to antioxidant activity. MRPs are known metal chelators $[25,28,31]$, and their metal-ion binding affinity has been proposed as a possible mechanism to explain their antioxidant activity [47] because transition metals, especially iron and copper, are involved in the generation of free radicals by Fenton reaction. The chelating activity of BSFL-Glu MRPs is shown in Figure 5. The chelating activity of BSFL-Glu conjugates increased significantly $(p<0.05)$ as a function of 


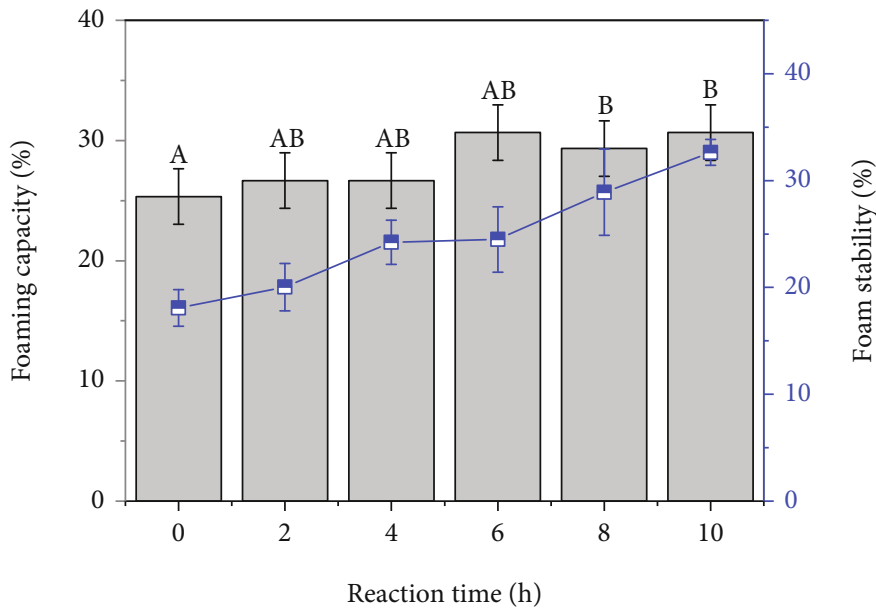

$\square$ Foaming capacity $50^{\circ} \mathrm{C}$

- - Foam stability $50^{\circ} \mathrm{C}$

(a)

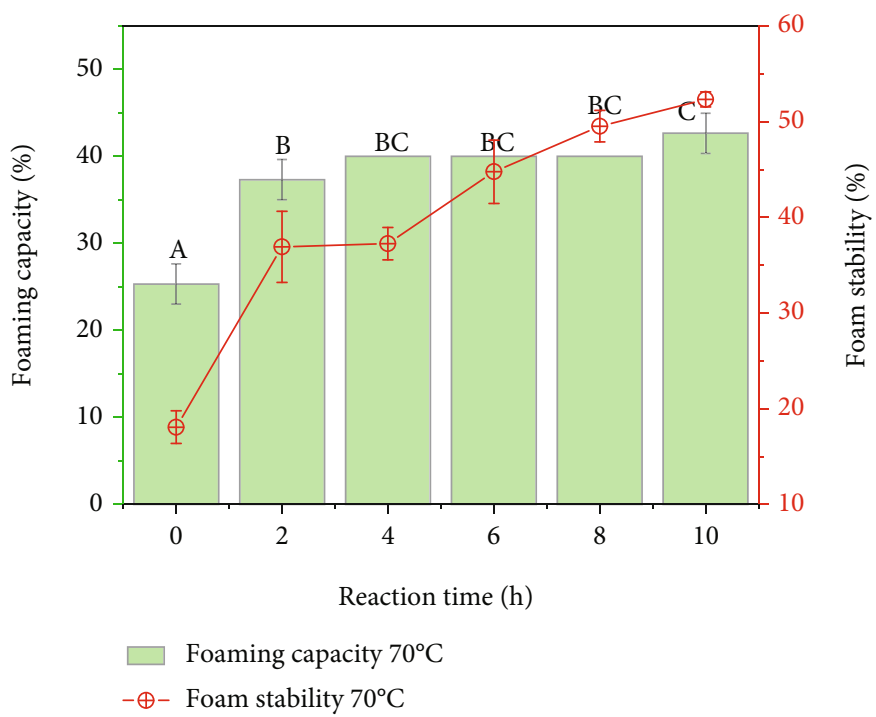

(b)

Figure 6: Continued. 


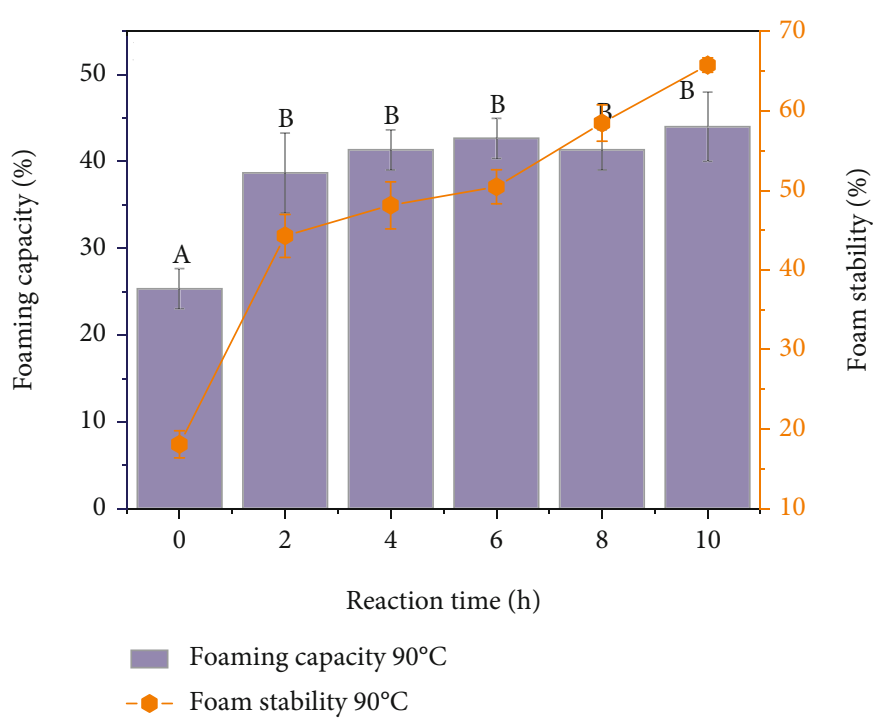

(c)

FIgURE 6: Foaming capacity and foam stability of BSFL-Glu conjugates as function of reaction time: (a) $50^{\circ} \mathrm{C}$, (b) $70^{\circ} \mathrm{C}$, and (c) $90^{\circ} \mathrm{C}$. Values are mean \pm standard deviation; means with different superscripts are significantly different at the same heating temperature.

reaction time and temperature. Chelating activity significantly increased from 17.20 to $28.20 \%$ for BSFL-Glu conjugates heated at $50^{\circ} \mathrm{C}$.

Generally, BSFL-Glu conjugates heated at $90^{\circ} \mathrm{C}$ exhibited higher metal chelation activity compared to those at $50^{\circ} \mathrm{C}$ and $70^{\circ} \mathrm{C}$. For the metal chelating activity of BSFL-Glu conjugates at $90^{\circ} \mathrm{C}$, a significant increase was observed until maximum $(64.45 \%)$ at $6 \mathrm{~h}$; this was then followed by a slight decrease until the end of the heating period. This implies that conjugates produced at $90^{\circ} \mathrm{C}$ for $6 \mathrm{~h}$ have the ability to inhibit lipid oxidation. Dong et al. [48] thought that the significant decrease in metal chelation of casein-glucose conjugates after $6 \mathrm{~h}$ could be partially due to the loss of free amine groups during thermal treatment. The results of this study coincide with the findings of Mshayisa [28] and Zeng et al. [23]. This decrease of metal chelation after $6 \mathrm{~h}$ can be ascribed to the formation of compounds with a high molecular weight at higher reaction temperatures and time. The results of this study are in agreement with Gu et al. [42], who observed high metal chelation of MRPs with a higher molecular weight in casein-glucose model systems. The observed chelating activity can be due to the hydroxyl groups originating from BSFL-Glu conjugates. Metal chelation activity plays an imperative role in antioxidant activity as it results in reducing the concentration of the transition metal which catalyses lipid oxidation $[49,50]$.

\section{Techno-Functional Properties}

5.1. Foaming Capacity and Stability. For items such as meringues, sponge cake, marshmallows, or ice creams, foaming properties are an essential techno-functional property of food protein ingredients. Therefore, knowledge of the foam capacity and stability of glycated edible insect protein is crucial in the quest for novel ingredients to be incorporated in food products. Figures $6(\mathrm{a})-6(\mathrm{c})$ illustrates the percentage of foam capacity (FC) and foam stability (FS) of conjugates derived from BSFL-Glu conjugates at $50^{\circ} \mathrm{C}, 70^{\circ} \mathrm{C}$, and $90^{\circ} \mathrm{C}$. All BSFL-Glu conjugates had the ability to form foams. In the case of BSFL-Glu conjugates heat-treated at $50^{\circ} \mathrm{C}$ (Figure 6(a)), the FC was not significantly $(p>0.05)$ different between 2 and $4 \mathrm{~h}$. The FC increased significantly $(p<0.05)$ after $6 \mathrm{~h}$ to a maximum of $30.67 \%$ and then decreased. However, the FS increased $(p<0.05)$ gradually during the heating period to a maximum of $32.64 \%$. Jian et al. [15] reported a decrease in foaming capacity of bovine serum albumin (BSA) conjugated with glucose at $45^{\circ} \mathrm{C}$. This apparent contradiction may be attributed to the differences in the protein hydrophobicity in the respective studies.

The foaming capacity of BSFL-Glu conjugates produced at $70^{\circ} \mathrm{C}$ showed a significant gradual increase $(p<0.05)$ from $2 \mathrm{~h}$ to $10 \mathrm{~h}$ (Figure 6(b)). Furthermore, the FS increased after $6 \mathrm{~h}$ to $42.66 \%$. The conjugates prepared at $70^{\circ} \mathrm{C}$ performed better in terms of FC and FS compared to those at $50^{\circ} \mathrm{C}$. BSFL-Glu conjugates treated at $90^{\circ} \mathrm{C}$ for $10 \mathrm{~h}$ showed superior foaming capacity (44\%) compared to the conjugates heated for shorter times. A similar trend was also observed in the foam stability at $90^{\circ} \mathrm{C}$ (Figure 6(c)). This can be attributed to the formation of a viscoelastic thick and dense layer around the entrapped air bubble interface and preventing the foam from collapsing. In general, the results of this study reveal that the foams derived from BSFL-Glu conjugates heated for longer periods (e.g. $10 \mathrm{~h}$ ) were considerably more stable, compared to those obtained at shorter reaction times, irrespective of the temperature. This is due to the modulation of the hydrophilic-lipophilic balance of proteins and the creation of conjugates with the inherent capability to entrap air bubbles during foam formation and retain them for longer periods by the Maillard reaction. These results were consistent with several previous reports showing that foaming capacity increased after glycation $[20,51,52]$ due to changed hydrophobicity and conformation after glycation. This work 


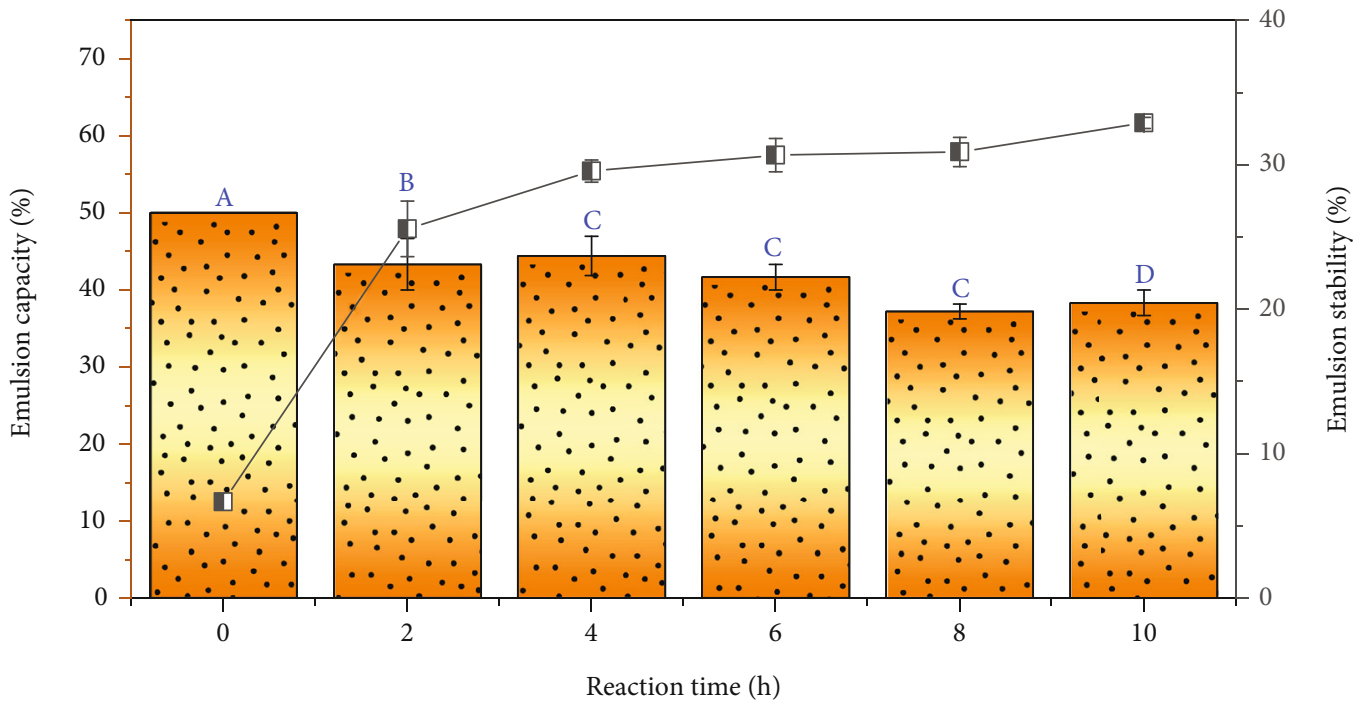

(a)

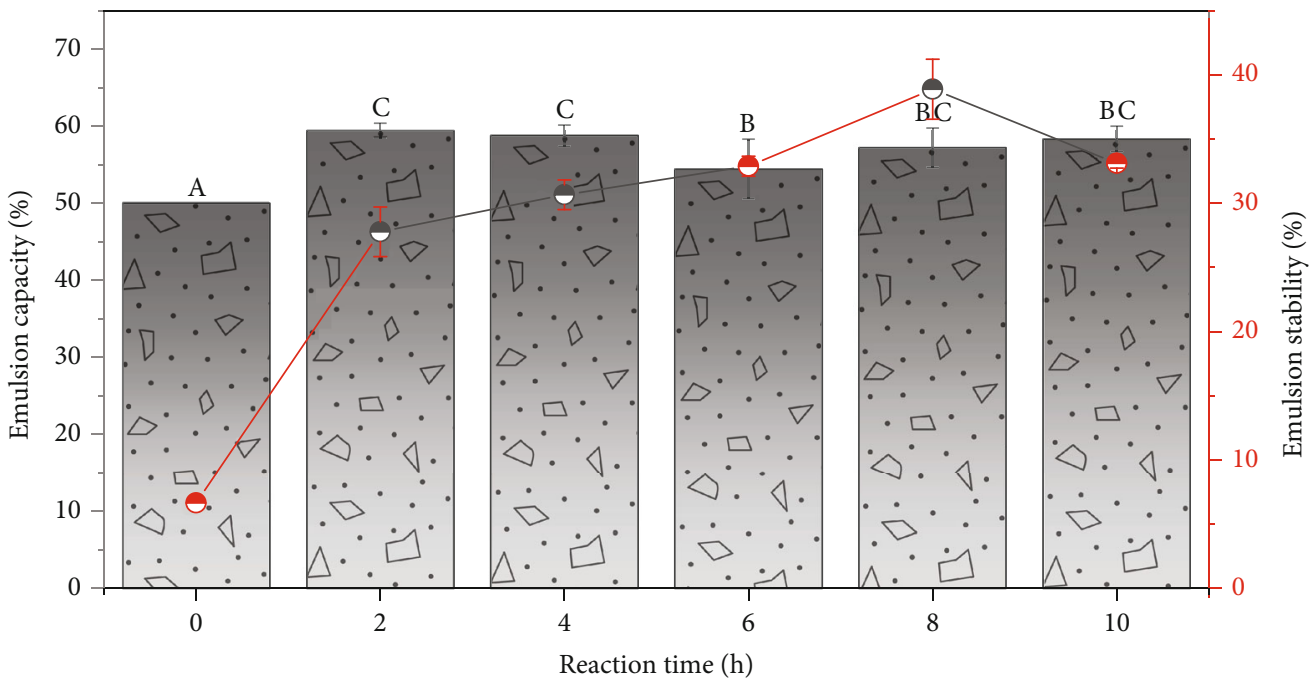

Emulsion capacity $70^{\circ} \mathrm{C}$

-๑- Emulsion stability $70^{\circ} \mathrm{C}$

(b)

Figure 7: Continued. 


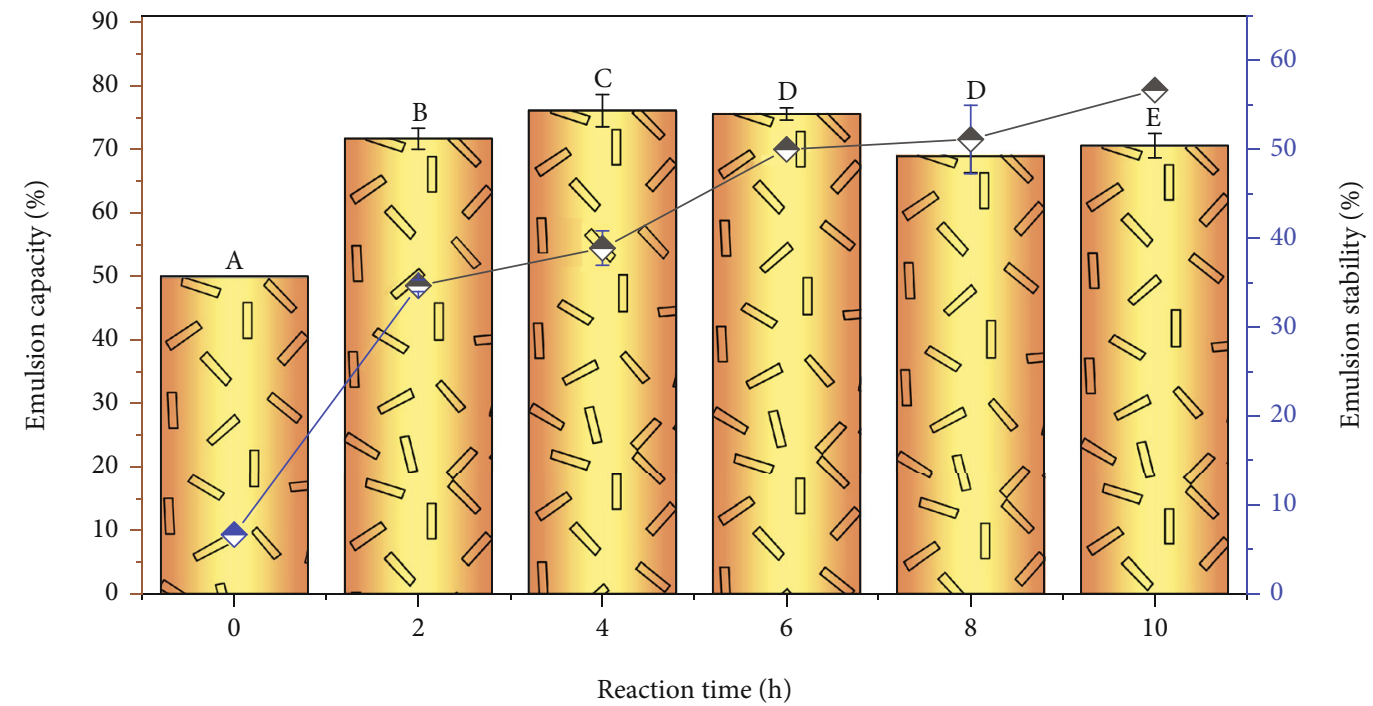

(c)

Figure 7: Emulsion capacity and stability of BSFL-Glu conjugates: (a) $50^{\circ} \mathrm{C}$, (b) $70^{\circ} \mathrm{C}$, and (c) $90^{\circ} \mathrm{C}$. Values are mean \pm standard deviation; means with different superscript are significantly different at the same heating temperature.

further demonstrates that glycation improved the technofunctional properties of proteins. Thus, modified BSFL protein via glycation could be used as a functional ingredient in food applications where foaming properties are desirable.

5.2. Emulsion Capacity and Stability. In food systems, emulsifying properties play an important role since they directly contribute to the texture and the organoleptic properties of food. They are also essential ingredients in the formation of structures in various food products, such as mayonnaise and dressings, coffee creamers, gravies, cream liqueurs, some fruit drinks, and many meat products. The emulsion capacity and stability of BSFL-Glu conjugates are depicted in Figures $7(\mathrm{a})-7(\mathrm{c})$. The emulsifying capacity of BSFL-Glu conjugates derived at $50^{\circ} \mathrm{C}$ decreased significantly $(p<0.05)$ as the reaction time increased. The control $(t=0)$ had a significantly higher $(p<0.05)$ emulsion capacity compared to the conjugates. However, emulsion stability increased significantly $(p<0.05)$ as the reaction time increased. These observations were inconsistent with those reported by Rangsansarid et al. [53], namely, that no improvements in emulsion stability were observed for BSA-sugar (glucose, allose, and 6-O-octanoyl-D-glucose) conjugates. On the contrary, BSFL-conjugates prepared at higher temperatures, for example, 70 and $90^{\circ} \mathrm{C}$ had significantly higher emulsion capacity compared with the control $(t=0)$. The emulsion capacity of BSFL-Glu conjugates at $70^{\circ} \mathrm{C}$ ranged from 54.44 to $59.45 \%$. The emulsion stability increased significantly $(p<0.05)$ as a function of reaction time, with conjugates produced after $8 \mathrm{~h}$ exhibiting the highest emulsion stability (35.89\%). In general, the emulsion stability of the conjugates increased significantly $(p<0.05)$ as a function of time, irrespective of glycation temperature. The reduction in interfacial tension by the emulsifier is mainly achieved by directing the hydrophobic and hydrophilic parts of the emulsifier toward the nonpolar fraction (oil phase) and the polar component (water phase), respectively. To the knowledge of the authors, the data presented in Figures $7(\mathrm{a})-7$ (c) is a first for BSFLbased conjugates and thus enriches the current literature on the potential incorporation of edible insect-derived ingredients in the food supply chain.

In this study, the BSFL-Glu conjugated at $90^{\circ} \mathrm{C}$ showed higher emulsion capacity and stability due to the Maillard reaction. This increase can be attributed not only to an increase in the reactivity of the BSFL protein structure between the carbonyl group and the amino group but also to a greater unfolding of the BSFL protein structure, showing a higher number of reactive functional groups (lysine residues), favoured by high temperatures. Most notably, this is the first study, to our knowledge, to examine the effect of Maillard conjugation on insect protein, in particular black soldier fly larvae. The high emulsion stability and capacity of BSFL-Glu conjugates suggest that they have the potential to be used as novel functional ingredients in food processing.

\section{Principal Component Analysis}

6.1. Principal Components Explaining the Variability in BSFL-Glu Browning Index and Antioxidant Activity. Principal component analysis (PCA) was used to reduce the variability of data among the heat-treated conjugates. In principal component analysis, the original data matrix is converted to loadings and scores (tested parameters) vectors, whereby new variables-the principal components-were obtained. PCA was, therefore, applied to the browning indicators, $\mathrm{pH}$ reduction, and antioxidant properties of BSFL- 

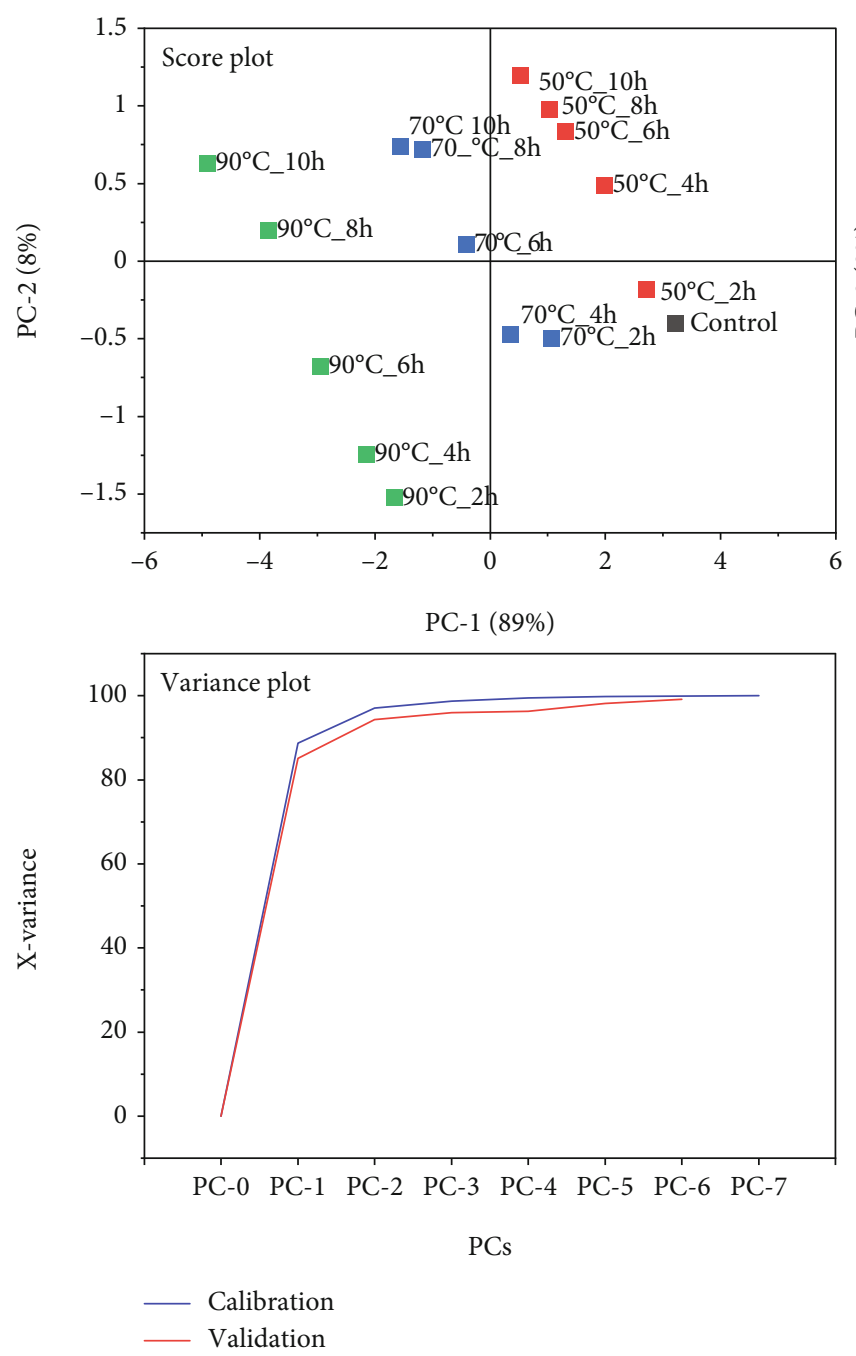

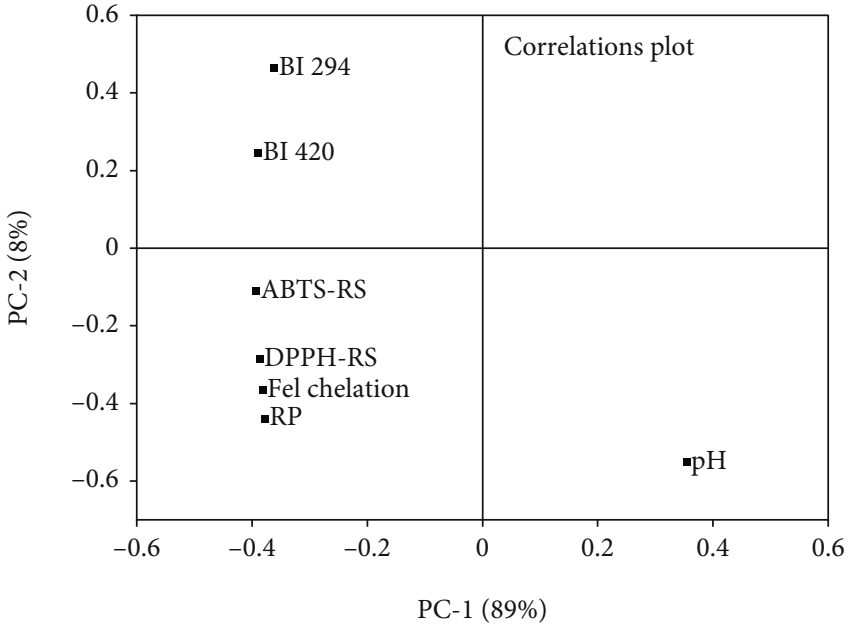

FIgURE 8: PCA plots of independent (scores) and dependent (loadings) variables for BSFL-Glu antioxidant indices.
Glu conjugates. The PCA exhibiting score, correlation loadings, explained variance, and influence plots are shown in Figure 8 . The explained variance plot gives an indication of how much variation in the data is described by the components. In this study, there is no clear break in the explained variance plot, which is the calibration is closer to the validation plot. The variability in the data could be explained by two PCs where PC1 contributes $89 \%$ of the variability and PC2 contributes $8 \%$ while PC3 explains $2 \%$. The cumulative variation explained by PC1 and PC2 was 97\% (Figure 8). Therefore, the first two PCs are sufficient to describe the variability in terms of BSFL-Glu conjugates in terms of the browning index and antioxidant properties.

Score plots were used for outlier identification, identification of groups or trends, exploration, of replicate similarities and more. The score plot showed that PC1 describes the heating temperature since samples are distributed from right to left according to the heating temperatures. Clusters of BSFL-Glu as a function of heating temperature could be clearly observed from the score plot. Moreover, the correlation loading matrix (Figure 8) shows that the outer ellipse explained $100 \%$ of the variability and while the inner ellipse indicates $50 \%$ of the explained variance. As can be seen from Figure 8 (top right), the browning index and antioxidant properties (DPPH-RS, ABTS-RS, Fe chelation and reducing power) were close to each other reflecting a high positive correlation with each other and overwhelmingly explained the $\mathrm{PC} 1$ direction. The $\mathrm{pH}$ reduction was diametrically opposed to the browning index and antioxidant properties. Therefore, these two components (PC1 and PC2) would be adequate for the prediction of browning and antioxidant indices of BSFLGlu conjugates.

6.2. Principal Components Explaining the Variability in BSFL-Glu Techno-Functional Properties. Principal component analysis was further used to determine the clusters or sample groupings concerning the techno-functional properties. From the explained variance plot, it can be deduced that two PCs are sufficient to explain the observed variance (Figure 9). The score plot indicates that cumulative variance explained by PC1 and PC2 were $85 \%$ and $11 \%$, respectively, with a total of $96 \%$. PC1 showed positive loadings in FC and FS, while PC 2 showed negative loading for EC. The PCA confirms the results obtained with regard to the heating 

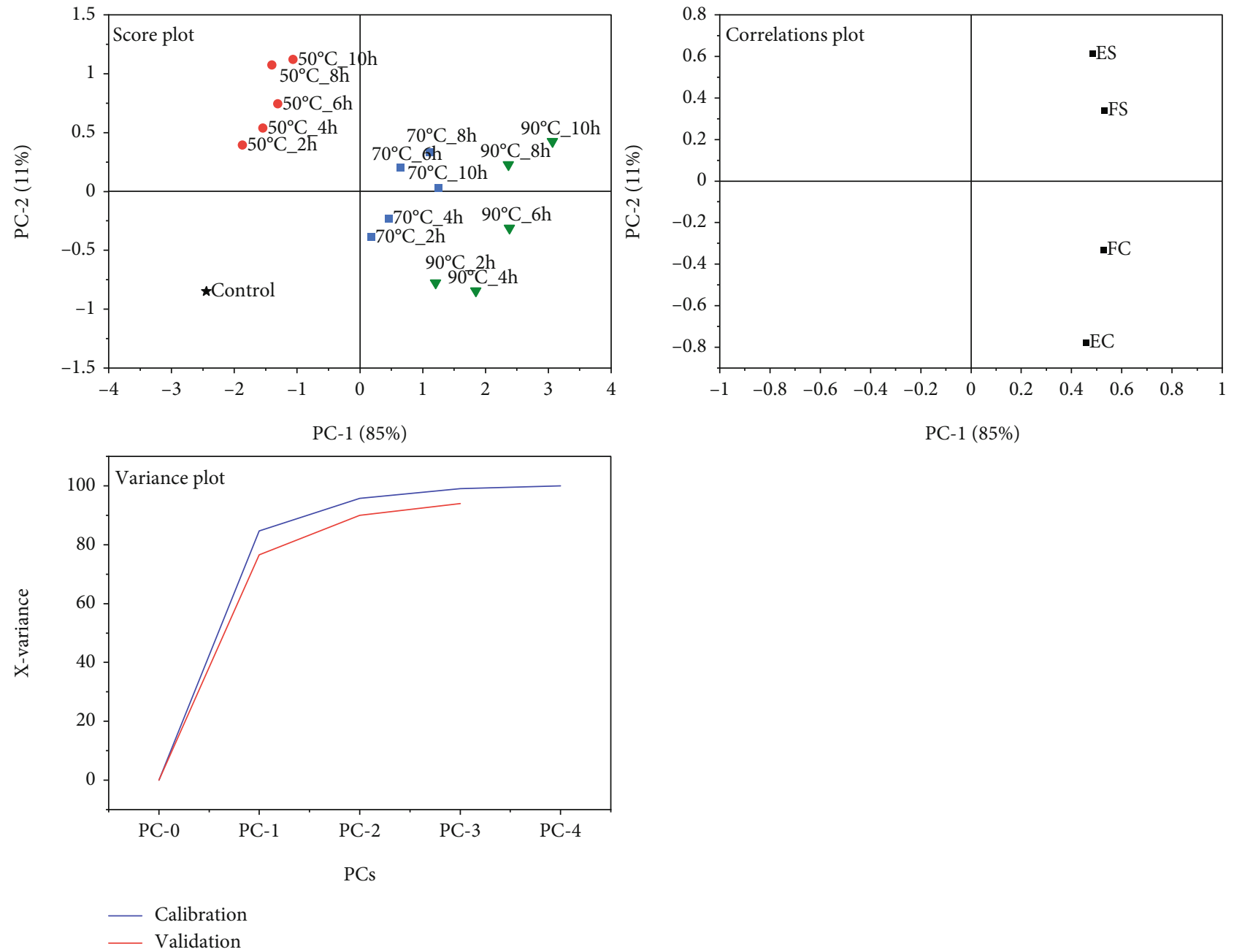

FIGURE 9: PCA plots of independent (scores) and dependent (loadings) variables for techno-functional properties.

temperature. From the model applied, the BSFL-Glu samples could be clearly separated into clusters based on the heating temperature.

\section{Conclusion}

The effect of heating temperature and time on the antioxidant and techno-functional properties of BSFL-Glu conjugates was demonstrated in the current study. Browning intensity, DPPH-RS and ABTS-RS radical scavenging activity consistently increased with an increase in reaction temperature and time. BSFL-Glu conjugates exhibited enhanced techno-functional properties, especially foaming stability and emulsion stability. The findings presented to demonstrate the use of conjugation through the Maillard reaction as an approach to enhance the functionality of proteins, which is particularly applicable to highly sought-after edible insect proteins. The performance of the BSFL-Glu conjugates in applications such as foams and emulsions need to be explored in future studies via more time-temperature combinations, since it was shown that heating time and temperature influence the extent of the glycation reaction. The results of this study indicated that protein conjugates of edible insects (BSFL) have significant potential for use as functional ingredients for the development of an effective foam and emulsion structure. Nevertheless, the effects on these conjugates with variation in $\mathrm{pH}$ and salts need to be examined in future work.

\section{Data Availability}

Data can be provided upon request.

\section{Conflicts of Interest}

The authors declare that they have no conflicts of interest.

\section{References}

[1] A. Van-Huis, "Potential of insects as food and feed in assuring food security," Annual Review of Entomology, vol. 58, no. 1, pp. 563-583, 2013.

[2] L. Kouřimská and A. Adámková, "Nutritional and sensory quality of edible insects," NFS Journal, vol. 4, pp. 22-26, 2016. 
[3] A. Van-Huis and F. V. Dunkel, "Edible insects: a neglected and promising food source," in Sustain. Protein Sources, pp. 341355, Elsevier Inc., 2016.

[4] J. A. C. Ortiz, A. T. Ruiz, M. Thomas et al., "Insect mass production technologies," in Insects as Sustain. Food Ingredients, pp. 153-201, Elsevier Inc., 2016.

[5] A. Gravel and A. Doyen, "The use of edible insect proteins in food: challenges and issues related to their functional properties," Innovative Food Science and Emerging Technologies, vol. 59, article 102272, 2020.

[6] S. Mancini, R. Moruzzo, F. Riccioli, and G. Paci, "European consumers' readiness to adopt insects as food. A review," Food Research International, vol. 122, pp. 661-678, 2019.

[7] H. S. G. Tan, A. R. H. Fischer, H. C. M. van Trijp, and M. Stieger, "Tasty but nasty? Exploring the role of sensoryliking and food appropriateness in the willingness to eat unusual novel foods like insects," Food Quality and Preference, vol. 48, pp. 293-302, 2016.

[8] H. Hu, J. Wu, E. C. Y. Li-Chan et al., "Effects of ultrasound on structural and physical properties of soy protein isolate (SPI) dispersions," Food Hydrocolloids, vol. 30, no. 2, pp. 647-655, 2013.

[9] Z. F. Zhou, Z. X. Ren, H. Y. Yu, J. Q. Jia, and Z. Z. Gui, “Effects of different modification techniques on molecular structure and bioactivity of Bombyx mori pupa protein," Journal of Asia-Pacific Entomology, vol. 20, no. 1, pp. 35-41, 2017.

[10] B. Purschke, P. Meinlschmidt, C. Horn, O. Rieder, and H. Jäger, "Improvement of techno-functional properties of edible insect protein from migratory locust by enzymatic hydrolysis," European Food Research and Technology, vol. 244, no. 6, pp. 999-1013, 2018.

[11] Y.-J. Son, J.-C. Lee, I.-K. Hwang, C. W. Nho, and S.-H. Kim, "Physicochemical properties of mealworm (Tenebrio molitor) powders manufactured by different industrial processes," LWT - Food Science and Technology, vol. 116, article 108514, 2019.

[12] N. Cheetangdee and K. Fukada, "Emulsifying activity of bovine $\beta$-lactoglobulin conjugated with hexoses through the Maillard reaction," Colloids and Surfaces A: Physicochemical and Engineering Aspects, vol. 450, pp. 148-155, 2014.

[13] C. Jia, D. Cao, S. Ji, W. Lin, X. Zhang, and B. Muhoza, "Whey protein isolate conjugated with xylo-oligosaccharides via maillard reaction: characterization, antioxidant capacity, and application for lycopene microencapsulation," LWT - Food Science and Technology, vol. 118, article 108837, 2020.

[14] Y. Tu, Y. Xu, F. Ren, and H. Zhang, "Characteristics and antioxidant activity of Maillard reaction products from $\alpha$-lactalbumin and $2^{\prime}$-fucosyllactose," Food Chemistry, vol. 316, article 126341, 2020.

[15] W. Jian, J. He, Y. Sun, and J. Pang, "Comparative studies on physicochemical properties of bovine serum albumin-glucose and bovine serum albumin-mannose conjugates formed via Maillard reaction," LWT - Food Science and Technology, vol. 69, pp. 358-364, 2016.

[16] J. Liu, Q. Xu, J. Zhang, P. Zhao, and Y. Ding, "Characterization of silver carp (Hypophthalmichthys molitrix) myosin protein glycated with konjac oligo-glucomannan," Food Hydrocolloids, vol. 57, pp. 114-121, 2016.

[17] F. Zha, S. Dong, J. Rao, and B. Chen, "The structural modification of pea protein concentrate with gum Arabic by controlled Maillard reaction enhances its functional properties and flavor attributes," Food Hydrocolloids, vol. 92, pp. 30-40, 2019.
[18] A. Medrano, C. Abirached, L. Panizzolo, P. Moyna, and M. C. Añon, "The effect of glycation on foam and structural properties of $\beta$-lactoglobulin," Food Chemistry, vol. 113, no. 1, pp. 127-133, 2009.

[19] N. Diftis and V. Kiosseoglou, "Improvement of emulsifying properties of soybean protein isolate by conjugation with carboxymethyl cellulose," Food Chemistry, vol. 81, no. 1, pp. 1-6, 2003.

[20] F. Chevalier, J. M. Chobert, Y. Popineau, M. G. Nicolas, and T. Haertlé, "Improvement of functional properties of $\beta$-lactoglobulin glycated through the Maillard reaction is related to the nature of the sugar," International Dairy Journal, vol. 11, no. 3, pp. 145-152, 2001.

[21] C. M. Oliver, L. D. Melton, and R. A. Stanley, "Creating proteins with novel functionality via the Maillard reaction: a review," Critical Reviews in Food Science and Nutrition, vol. 46, no. 4, pp. 337-350, 2006.

[22] S. Dong, A. Panya, M. Zeng, B. Chen, D. J. Mcclements, and E. A. Decker, "Characteristics and antioxidant activity of hydrolyzed $\beta$-lactoglobulin-glucose Maillard reaction products,” FRIN, vol. 46, no. 1, pp. 55-61, 2012.

[23] Y. Zeng, X. Zhang, Y. Guan, and Y. Sun, "Characteristics and antioxidant activity of Maillard reaction products from psicose-lysine and fructose-lysine model systems," Journal of Food Science, vol. 76, no. 3, pp. C398-C403, 2011.

[24] H. Kchaou, N. Benbettaïeb, M. Jridi et al., "Enhancement of structural, functional and antioxidant properties of fish gelatin films using Maillard reactions," Food Hydrocolloids, vol. 83, pp. 326-339, 2018.

[25] L. N. Vhangani and J. Van-Wyk, "Antioxidant activity of Maillard reaction products (MRPs) derived from fructose-lysine and ribose-lysine model systems," Food Chemistry, vol. 137, no. 1-4, pp. 92-98, 2013.

[26] Karseno, Erminawati, T. Yanto, R. Setyowati, and P. Haryanti, "Effect of $\mathrm{pH}$ and temperature on browning intensity of coconut sugar and its antioxidant activity," Food Research, vol. 2, pp. 32-38, 2018.

[27] F. Guérard and M.-T. Sumaya-Martinez, "Antioxidant effects of protein hydrolysates in the reaction with glucose," Journal of the American Oil Chemists' Society, vol. 80, no. 5, pp. 467470, 2003.

[28] V. V. Mshayisa, “Antioxidant effects of Maillard reaction products (MRPs) derived from glucose-casein model systems (MTech Thesis)," Thesis, Cape Town, South Africa, 2016, http://hdl.handle.net/20.500.11838/2505.

[29] W. Lertittikul, S. Benjakul, and M. Tanaka, "Characteristics and antioxidative activity of Maillard reaction products from a porcine plasma protein-glucose model system as influenced by pH," Food Chemistry, vol. 100, no. 2, pp. 669-677, 2007.

[30] X. Yu, M. Zhao, J. Hu, S. Zeng, and X. Bai, “Correspondence analysis of antioxidant activity and UV-Vis absorbance of Maillard reaction products as related to reactants," $L W T$ Food Science and Technology, vol. 46, no. 1, pp. 1-9, 2012.

[31] F. Gu, J. M. Kim, S. Abbas, X. Zhang, S. Xia, and Z. Chen, "Structure and antioxidant activity of high molecular weight Maillard reaction products from casein-glucose," Food Chemistry, vol. 120, no. 2, pp. 505-511, 2010.

[32] E. Zielińska, M. Karaś, and B. Baraniak, "Comparison of functional properties of edible insects and protein preparations thereof," LWT - Food Science and Technology, vol. 91, pp. $168-174,2018$. 
[33] M. S. Coelho and M. de las Mercedes Salas-Mellado, "How extraction method affects the physicochemical and functional properties of chia proteins," LWT - Food Science and Technology, vol. 96, pp. 26-33, 2018.

[34] C. Anzani, C. Álvarez, and A. M. Mullen, “Assessing the effect of Maillard reaction with dextran on the techno-functional properties of collagen-based peptides obtained from bovine hides," LWT - Food Science and Technology, vol. 118, article 108800, 2020.

[35] S. Benjakul, W. Lertittikul, and F. Bauer, "Antioxidant activity of Maillard reaction products from a porcine plasma proteinsugar model system," Food Chemistry, vol. 93, no. 2, pp. 189196, 2005.

[36] J. You, Y. Luo, H. Shen, and Y. Song, "Effect of substrate ratios and temperatures on development of Maillard reaction and antioxidant activity of silver carp (Hypophthalmichthys molitrix) protein hydrolysate-glucose system," International Journal of Food Science and Technology, vol. 46, no. 12, pp. 24672474, 2011.

[37] Z. Z. Xu, G. Q. Huang, T. C. Xu, L. N. Liu, and J. X. Xiao, "Comparative study on the Maillard reaction of chitosan oligosaccharide and glucose with soybean protein isolate," International Journal of Biological Macromolecules, vol. 131, pp. 601-607, 2019.

[38] K. Matmaroh, "Effect of reactant concentrations on the Maillard reaction in a fructose-glycine model system and the inhibition of black tiger shrimp polyphenoloxidase," Food Chemistry, vol. 98, no. 1, pp. 1-8, 2006.

[39] W. Q. Wang, Y. H. Bao, Y. Chen, W. Wen-qiong, B. Yi-hong, and C. Ying, "Characteristics and antioxidant activity of watersoluble Maillard reaction products from interactions in a whey protein isolate and sugars system," Food Chemistry, vol. 139, no. 1-4, pp. 355-361, 2013.

[40] L. N. Vhangani and J. Van-Wyk, "Antioxidant activity of Maillard reaction products (MRPs) in a lipid-rich model system," Food Chemistry, vol. 208, pp. 301-308, 2016.

[41] Z. Jiang, D. K. Rai, P. M. O. Connor, and A. Brodkorb, "Heatinduced Maillard reaction of the tripeptide IPP and ribose: structural characterization and implication on bioactivity," FRIN, vol. 50, pp. 266-274, 2013.

[42] F. Gu, J. M. Kim, K. Hayat, S. Xia, B. Feng, and X. Zhang, "Characteristics and antioxidant activity of ultrafiltrated Maillard reaction products from a casein-glucose model system," Food Chemistry, vol. 117, no. 1, pp. 48-54, 2009.

[43] Y. Sun, S. Hayakawa, S. Puangmanee, and K. Izumori, "Chemical properties and antioxidative activity of glycated $\alpha$-lactalbumin with a rare sugar, D-allose, by Maillard reaction," Food Chemistry, vol. 95, no. 3, pp. 509-517, 2006.

[44] H. Wang, H. Qian, and W. Yao, "Melanoidins produced by the Maillard reaction: structure and biological activity," Food Chemistry, vol. 128, no. 3, pp. 573-584, 2011.

[45] M. Nooshkam, M. Varidi, and M. Bashash, "The Maillard reaction products as food-born antioxidant and antibrowning agents in model and real food systems," Food Chemistry, vol. 275, pp. 644-660, 2019.

[46] Y. Yoshimura, T. Iijima, T. Watanabe, and H. Nakazawa, "Antioxidative effect of Maillard reaction products using glucose-glycine model system," Journal of Agricultural and Food Chemistry, vol. 8561, pp. 4106-4109, 1997.

[47] H. Jing and D. D. Kitts, "Antioxidant activity of sugar-lysine Maillard reaction products in cell free and cell culture sys- tems," Archives of Biochemistry and Biophysics, vol. 429, no. 2, pp. 154-163, 2004.

[48] S. Dong, B. Wei, B. Chen, D. J. McClements, and E. A. Decker, "Chemical and antioxidant properties of casein peptide and its glucose Maillard reaction products in fish oil-in-water emulsions," Journal of Agricultural and Food Chemistry, vol. 59, no. 24, pp. 13311-13317, 2011.

[49] C. Delgado-Andrade, I. Seiquer, and M. P. Navarro, "Bioavailability of iron from a heat treated glucose-lysine model food system: assays in rats and in Caco-2 cells," Journal of the Science of Food and Agriculture, vol. 84, no. 12, pp. 1507-1513, 2004.

[50] S. P. Chawla, R. Chander, and A. Sharma, "Antioxidant formation by $\gamma$-irradiation of glucose-amino acid model systems," Food Chemistry, vol. 103, no. 4, pp. 1297-1304, 2007.

[51] A. Achouri, J. I. Boye, D. Belanger, T. Chiron, V. A. Yaylayan, and F. K. Yeboah, "Functional and molecular properties of calcium precipitated soy glycinin and the effect of glycation with $\kappa$-carrageenan," Food Research International, vol. 43, no. 5, pp. 1494-1504, 2010.

[52] L. E. Garcia-Amezquita, M. S. Martinez-Alvarenga, G. I. Olivas, P. B. Zamudio-Flores, C. H. Acosta-Muñiz, and D. R. Sepulveda, "Effect of Maillard reaction conditions on the degree of glycation and functional properties of whey protein isolate - Maltodextrin conjugates," Food Hydrocolloids, vol. 38, pp. 110-118, 2014.

[53] J. Rangsansarid, N. Cheetangdee, N. Kinoshita, and K. Fukuda, "Bovine serum albumin-sugar conjugates through the Maillard reaction: effects on interfacial behavior and emulsifying ability," Journal of Oleo Science, vol. 57, no. 10, pp. 539-547, 2008 . 